\title{
Transection with pseudoaneurysm formation of the pulmonary trunk after placement of an adjustable pulmonary artery banding device (FloWatch-PAB) in a patient with residual muscular ventricular septal defect
}

Prem S. Venugopal, MCh, FRCS, Nicholas Hayes, MRCPCH, John Simpson, FRCP, and David Anderson, FRCS, London, United Kingdom

$$
\begin{aligned}
& \text { TCM } \\
& \text { VIDEO Video clip is available online. } \\
& \text { CLIP }
\end{aligned}
$$

A remotely adjustable pulmonary artery (PA) band has the advantage of adjusting the pulmonary gradient based on hemodynamic requirements. FloWatch-PAB (EndoArt S.A., Lausanne, Switzerland) has been used in more than $67 \mathrm{pa}-$ tients for various indications. ${ }^{1}$ We report a case of transection of the main PA with pseudoaneurysm formation after the insertion of the FloWatch-PAB device.

\section{CLINICAL SUMMARY}

A 6-month-old girl weighing $6 \mathrm{~kg}$ underwent closure of an inlet muscular ventricular septal defect (VSD). Postoperatively, she was found to have a hemodynamically signifi-

From Congenital Heart Surgery, Guy's \& St Thomas NHS Foundation Trust, London, United Kingdom

Disclosures: None.

Received for publication Jan 20, 2009; revisions received Feb 7, 2009; accepted for publication March 2, 2009; available ahead of print May 18, 2009.

Address for reprints: Prem S. Venugopal, MCh, FRCS, Congenital Heart Surgery, Guy's \& St Thomas NHS Foundation Trust, 20, Stangate, Royal St, London SE1

7EQ, United Kingdom (E-mail: vpremsundar@gmail.com).

J Thorac Cardiovasc Surg 2010;139:e103-4

$0022-5223 / \$ 36.00$

Copyright (c) 2010 by The American Association for Thoracic Surgery

doi:10.1016/j.jtcvs.2009.03.002 cant residual VSD, and the child was ventilator dependent. She went on to have a FloWatch-PAB adjustable PA band placed. On the third postoperative day, resternotomy was performed for cardiac tamponade. No surgical cause for the tamponade was identified. Subsequently, the child made an uneventful recovery and was discharged on the 12th postoperative day. Six weeks later, the PA band was remotely readjusted, increasing the Doppler velocity across the band from $3 \mathrm{~m} / \mathrm{s}$ to $3.7 \mathrm{~m} / \mathrm{s}$ and the constriction from $50 \%$ to $60 \%$. A week after this, her PA pressure was found to be suprasystemic, and she was found to have a pseudoaneurysm of the PA. She was transferred to our center for further management. Investigations that included a chest skiagram, computed tomographic analysis, and 2- and 3dimensional echocardiographic analysis revealed that she had a large pseudoaneurysm of the PA, with the device floating freely in the pseudoaneurysm cavity (Figure 1; Videos 1 and 2, available online). There was also a significant residual VSD. She was taken for surgical intervention, and intraoperatively, the device was seen to have completely eroded through the main PA and was lying freely inside the pseudoaneurysm cavity, with the blood contained in this thin-walled cavity (Figure 2). The residual VSD was closed transatrially with a polytetrafluoroethylene patch, the pseudoaneurysm cavity was resected, and the PA was reconstructed by an end-to-end anastomosis. The patient's postoperative recovery was uneventful, and she was discharged to her local hospital on the 12th postoperative day.
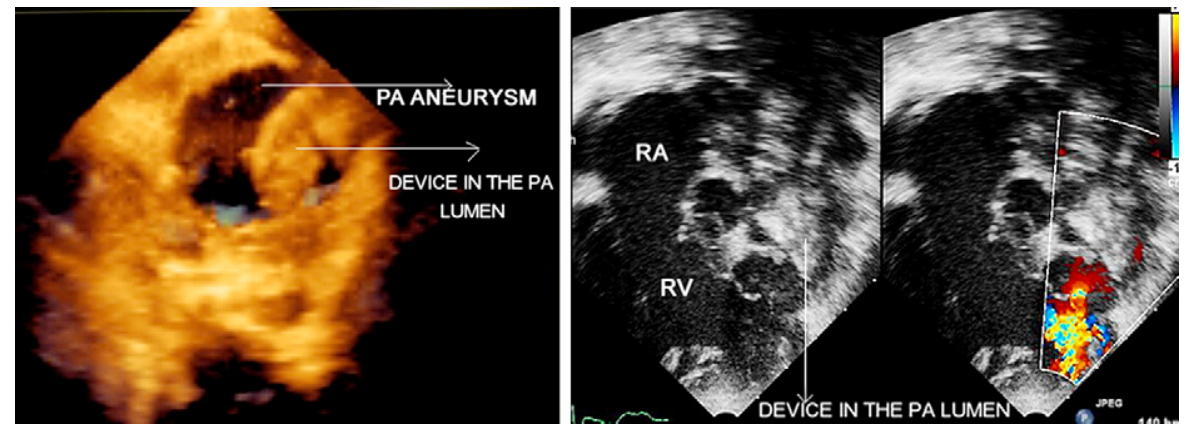

FIGURE 1. Two-dimensional echocardiographic analysis with Doppler scanning and 3-dimesnional echocardiographic analysis showing the pulmonary artery $(P A)$ band device in the lumen of the pulmonary artery. $R A$, Right atrium; $R V$, right ventricle. 

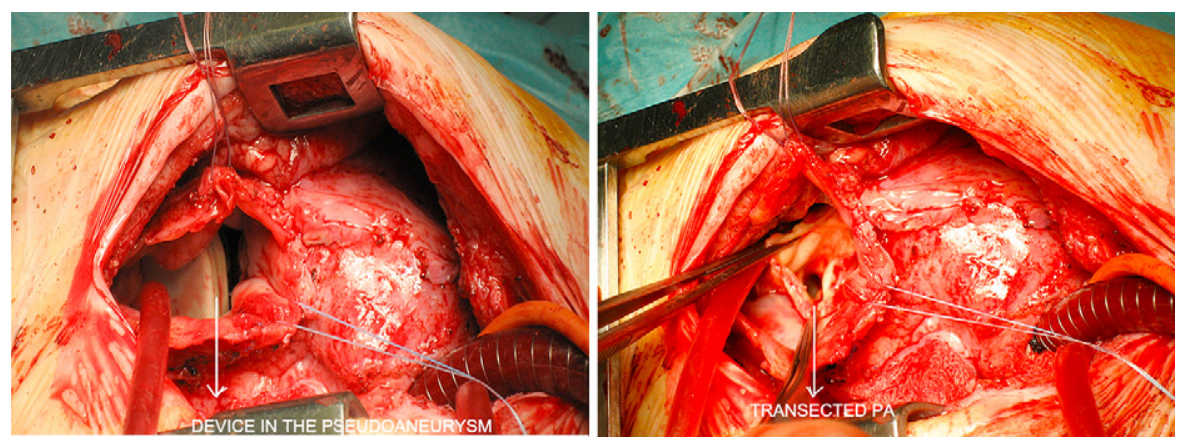

FIGURE 2. Intraoperative picture showing transection of the pulmonary artery and the device in the pulmonary artery lumen.

\section{DISCUSSION}

This case is reported to highlight the possibility of erosion and pseudoaneurysm formation after implantation of the FloWatch-PAB adjustable PA banding system. As far as we are aware, this is the second such complication with this device. ${ }^{2}$ The previous reported case had a similar complication, with pseudoaneurysm formation 7 weeks after the insertion. Doubts have been raised about the technical aspect of insertion being the cause for the pseudoaneurysm formation. ${ }^{1}$ In our case no intraoperative difficulty was reported. We therefore would like to highlight this specific occurrence of a pseudoaneurysm of the PA as a possible complication of the device rather than a problem with the technique of insertion. We would recommend anyone having this device inserted to have regular and frequent follow-up until the device is removed.

\section{References}

1. Corno AF, Pozzi M, Von Segesser LK. Flowatch and pseudoaneurysm: complication versus coincidence. J Thorac Cardiovasc Surg. 2006;131:928-9.

2. Michel-Behnke I, Akintuerk H, Valeske K, Thul J, Mueller M, Schranz D. Pseudoaneurysm of the pulmonary trunk after placement of an adjustable pulmonary artery banding device (FloWatch-PAB) in a patient with muscular ventricular septal defect. J Thorac Cardiovasc Surg. 2005;130:894-5.

\title{
An adult man presenting with hemoptysis caused by mature teratoma with rupture into the bronchus and pericardium and complicated by Haemophilus influenzae infection
}

\author{
Karthik Jothianandan, MD, ${ }^{\mathrm{a}}$ Amit S. Tibb, MD, ${ }^{\mathrm{b}}$ Michael McLemore, MD, ${ }^{\mathrm{c}}$ Steven Keller, $\mathrm{MD},{ }^{\mathrm{d}}$ and \\ David W. Appel, MD, ${ }^{\mathrm{b}}$ Bronx, NY
}

Mediastinal mature teratomas in adults are uncommon, typically asymptomatic tumors that arise in the anterior mediastinum. ${ }^{1}$ Usually, they are benign and resectable. ${ }^{1,2}$ Rarely, they rupture into adjacent cardiothoracic struc-

\footnotetext{
From the Departments of Internal Medicine, ${ }^{\mathrm{a}}$ Pulmonary Medicine, ${ }^{\mathrm{b}}$ Pathology, ${ }^{\mathrm{c}}$ and Cardiothoracic Surgery, ${ }^{\mathrm{d}}$ Montefiore Medical Center, Bronx, NY. Disclosures: None.

Received for publication Feb 20, 2009; accepted for publication March 7, 2009; available ahead of print May 11, 2009.

Address for reprints: Karthik Jothianandan, MD, Internal Medicine, Montefiore Medical Center, 111 E 210 St, Bronx, NY 10467 (E-mail: karthik.jothi@gmail.com).

J Thorac Cardiovasc Surg 2010;139:e104-7 $0022-5223 / \$ 0.00$

Published by Elsevier Inc. on behalf of The American Association for Thoracic Surgery

doi:10.1016/j.jtcvs.2009.03.003
}

tures. ${ }^{1,2}$ Hemoptysis as a presenting symptom is rare. Among adults, bacterial infection complicating mediastinal mature teratoma rupture has not been described.

Herein we report the case of a 58-year-old man who presented with hemoptysis and was found to have an unresectable mediastinal mature teratoma with rupture into a bronchus, intrapericardial tumor extension surrounding the left and right ventricles, and simultaneous Haemophilus influenzae infection. A mediastinal mature teratoma in an adult with this complex presentation has not been described previously to our knowledge.

\section{CLINICAL SUMMARY}

A 58-year-old man from Ghana was hospitalized after 5 days of hemoptysis, cough, dyspnea, and pleuritic left chest 